\title{
Propagation channel characterization for Ka mobile communication systems
}

\author{
ISRAEL Jonathan \\ ONERA/DEMR \\ Université de Toulouse \\ F-31055 Toulouse, France \\ jonathan.israel@onera.fr
}

\author{
ROUGERIE Sébastien \\ CNES \\ French Space Agency \\ 31400 Toulouse, France \\ sébastien.rougerie@cnes.fr
}

\begin{abstract}
The statistical characterization of the propagation channel is of paramount importance in the design of future mobile satellite communication systems. At Ka band, the propagation channel can be strongly impacted by tropospheric events but also by the receiver local environment. Buildings, poles or trees can lead to partial or even total shadowing effects. In this paper, we present an extensive characterization of the local propagation effects in various environments such as urban, rural, highway or railway environments. The statistical analysis of measurements made in Ka band confirms and extends observations that have been made previously in comparable or lower frequency bands.

Index Terms-propagation, communication, frequency selectivity
\end{abstract}

\section{INTRODUCTION}

Recent land mobile communication services lead to strong requirements in terms of availability, performance and compactness at the receiver side. Therefore the use of satellites operating in the Ka band is constantly increasing. Thus, the characterization of the propagation channel and the related link budget in $\mathrm{Ka}$ band is a key aspect of the design of the corresponding systems. In satellite to earth transmissions, the signal is impacted while propagating through the atmosphere and is also affected by the local environment of the receiver. In this paper, we give a statistical characterization of the local effects in different environments thanks to a mobile measurement campaign of the Athena-Fidus satellite operating around $20 \mathrm{GHz}$.

\section{EXPERIMENTAL RESULTS}

The CNES OSCAR vehicle, Fig.1, has been used to record the signal emitted by the Athena-Fidus antenna transponder. The mobile set up was equipped with:

- a Gilat ER5000 Ka receiving antenna,

- an USRP N210 sampling at $1 \mathrm{MHz}$ or $25 \mathrm{MHz}$ the signal downconverted in L band,

- a GPS Ublox V8 receiver,

- an AH 950 wheel encoder,

- a Lady Bug fish eye camera.

Experiments were conducted in different environments (highway, rural, urban and railway) on long range trajectories over a total length of more thant 100 miles around Toulouse, France. We give in Fig.2 an example of trajectory on the Toulouse ring road. The power time series acquired from this Ka band

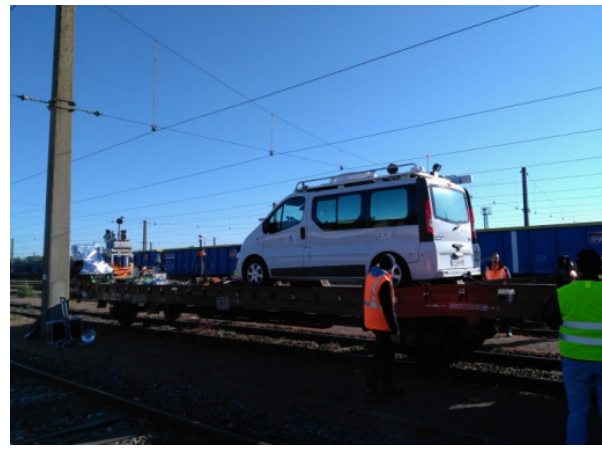

Fig. 1. Representation of the CNES OSCAR mobile receiver, here during the GEOFER experimental campaign in railway environment, [1].

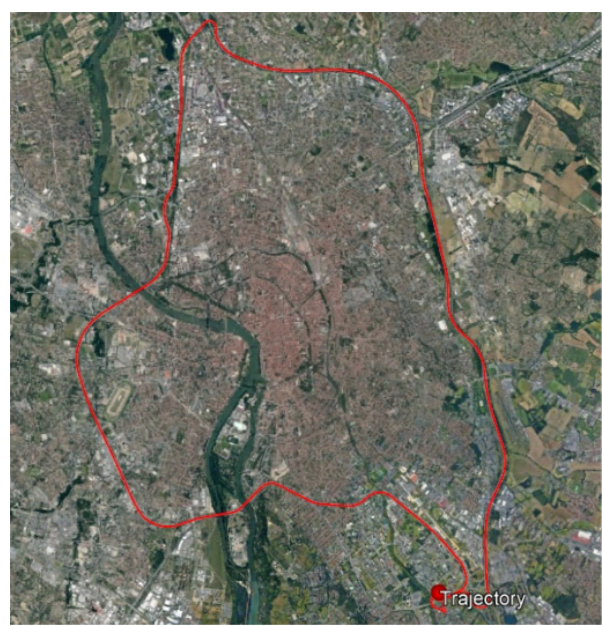

Fig. 2. A sample of highway trajectory on the Toulouse ring road.

mobile communication system exhibit characteristical profiles. In Line Of Sight situations (LOS), the received signal is largely dominated by the direct signal. We observe slight oscillations lower than $2 \mathrm{~dB}$, which are mainly due to the receiving antenna pointing system. The attenuation due to tree canopies ranges from $5 \mathrm{~dB}$ to $35 \mathrm{~dB}$ and is dependent to the tree species and leaves densities, Fig.3. Those values are coherent with typical linear attenuation that have already been measured or modeled at $20 \mathrm{GHz}$ and which are commonly in the order 

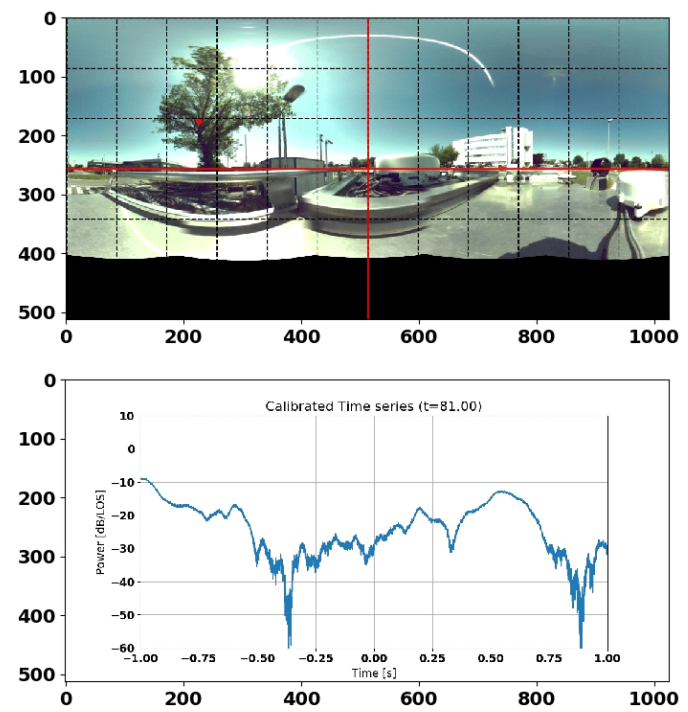

Fig. 3. Attenuation pattern when the LOS (red circle) is shadowed by a tree canopy.
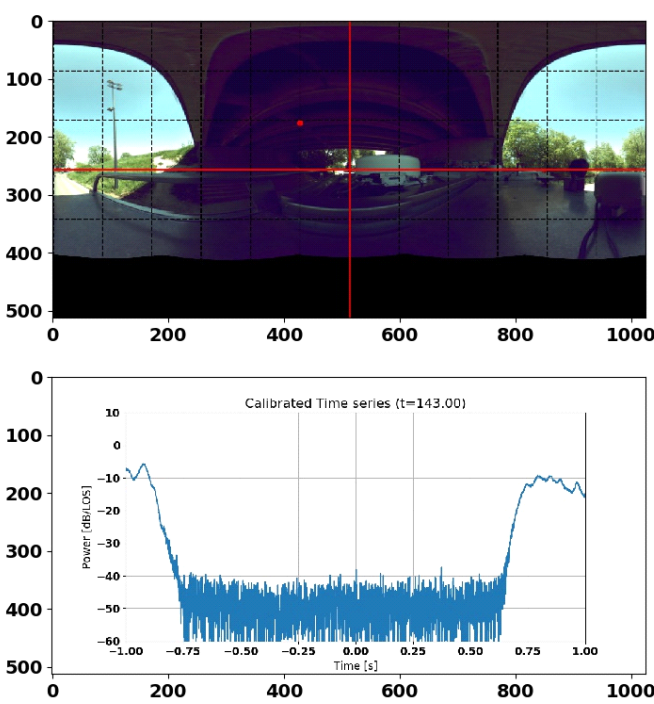

Fig. 4. Attenuation pattern when the LOS is obstructed by a blocking element such as a bridge.

of magnitude of a few $\mathrm{dB} / \mathrm{m}$, [2]. Buildings and large man made structures cause usually much stronger attenuations. In our case, they are above the system dynamic capacity, Fig.4. Hence, the attenuation $1 \%$ worth percentile (and even $10 \%$ worth percentile for urban environments) exceeds usual link margins of satellite systems operating in Ka band. Diffraction patterns due to catenary poles or tree trunks, Fig.5, show good agreements with previous experiments conducted on Astra 3B around $20.2 \mathrm{GHz}$, [3], leading to attenuations which range from $5 \mathrm{~dB}$ to $15 \mathrm{~dB}$, depending on the distance between the obstacle and the receiver. The Doppler effect due to the scene dynamic aspect (receiver and surrounding objects movements) induces a propagation channel modification that affects the
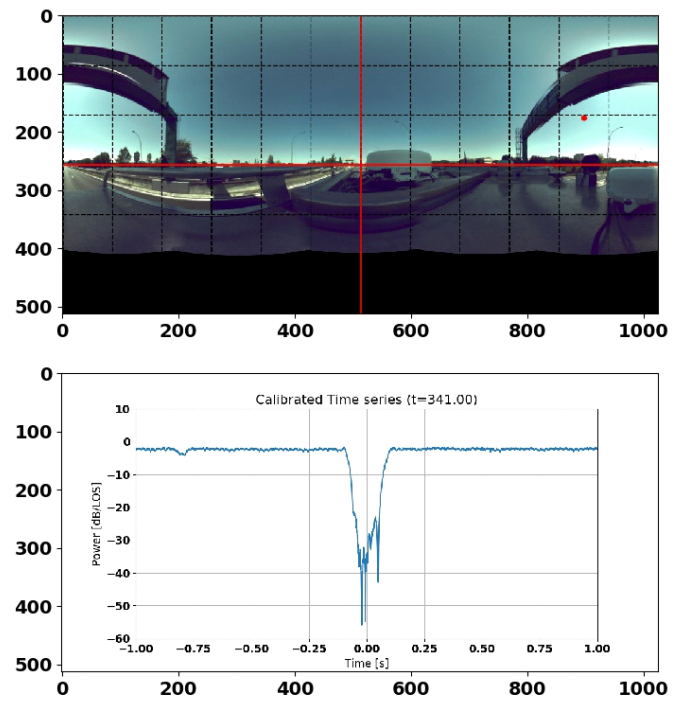

Fig. 5. Diffractive pattern due to a thin element such as a sign pole.

transmitted signal. The coherence time measures the capacity of the propagation channel to remain correlated in time despite the modifications induced by the Doppler effects. Assuming a stationary propagation channel, the local autocorrelation function is:

$$
C(\Delta t)=\int h(t) h^{*}(t-\Delta t) d t
$$

where $h(t)$ is the received narrow band time series. For a non stationary signal such as the mobile propagation channel, the autocorrelation is locally time sensitive and we can define the local time coherence at $\mathrm{N} \mathrm{dB}, T c_{N}\left(t_{0}\right)$ as:

$$
T c_{N}\left(t_{0}\right)=\underset{\Delta t}{\arg \max }\left(C_{t 0}(\Delta t)>C_{t 0}(0)-N\right)
$$

where $C_{t 0}$ is the local autocorrelation centered in t0 and expressed in $\mathrm{dB}$. In our case, we compute the time coherence at $15 \mathrm{~dB}$, this value being in the order of magnitude of attenuations around which a standard satellite communication can be lost. Accordingly, the Doppler spread is insignificant, lower than $5 \mathrm{~Hz}$ regardless of the environment, which is coherent with observations made previously in Ku band, [4]. Results on Doppler spread and time coherence show that the propagation channel exhibits no significant frequency selectivity in $\mathrm{Ka}$ band if directive antennas are used. Finally, the Level Crossing Rate at $15 \mathrm{~dB}$ ranges from $0.2 \mathrm{~Hz}$ to $0.7 \mathrm{~Hz}$, which is consistent with previous observations made in $\mathrm{Ku}$ band, [5] or Ka band, [6]. Several first and second order statistics have been extracted from the RF signal and are summarized in Fig. 6 for all the studied environments.

\section{CONCLUSION}

Those preliminary results show a good agreement with previous observations and extend their applicability, both in term of frequency and environments. Especially, they show that the mobile propagation channel exhibits no significant 


\begin{tabular}{|c|c|c|c|c|c|}
\hline \multicolumn{2}{|c|}{} & \multicolumn{5}{c|}{ Environment } \\
\cline { 3 - 6 } \multicolumn{2}{|c|}{} & Highway & Rural & Urban & Railway \\
\hline $\begin{array}{c}\text { Doppler spread } \\
(\mathrm{Hz})\end{array}$ & $99^{\text {th }}$ centile & 3.5 & 1.6 & 3.4 & 4.8 \\
\cline { 2 - 6 } & $90^{\text {th }}$ centile & $<0.1$ & $<0.1$ & $<0.1$ & $<0.1$ \\
\hline $\begin{array}{c}\text { Time coherence } \\
\text { @-15dB (ms) }\end{array}$ & $1^{\text {th }}$ centile & 3 & 4 & 3.5 & 4.6 \\
\cline { 2 - 6 } & $10^{\text {th }}$ centile & 14 & 14.5 & 14.4 & 17.3 \\
\hline \multirow{2}{*}{$\begin{array}{c}\text { Attenuation } \\
(\mathrm{dB})\end{array}$} & $1^{\text {th }}$ centile & $<-35$ & $<-35$ & $<-35$ & $<-35$ \\
\cline { 2 - 6 } & $10^{\text {th }}$ centile & -9 & -17.2 & $<-35$ & -3.4 \\
\hline \multicolumn{2}{|c|}{ Level Crossing Rate @-15dB (Hz) } & 0.3 & 0.7 & 0.5 & 0.2 \\
\hline
\end{tabular}

Fig. 6. Statistics extracted from the Athena-Fidus signal. $1 \%$ and $10 \%$ worst and most impacting values are given.

frequency selectivity when using typical directive antennas at the receiver side. Measurements from the GEOFER campaign, [1], are still under processing for an extensive characterization of the railway environment. Ongoing work is actually focusing on taking advantage of recent developments in deep learning in order to forward previous work on joint video / RF propagation channel characterization, [7].

\section{REFERENCES}

[1] "Et si les trains naviguaient avec galileo?" [Online]. Available: https://www.digital.sncf.com/actualites/et-si-les-trains-naviguaientavec-galileo

[2] J. Israel and A. Pajot, "Fading and scattering due to trees in 1 to ka band propagation simulations," in 2015 9th European Conference on Antennas and Propagation (EuCAP), May 2015, pp. 1-5.

[3] J. Lemorton, X. Boulanger, M. A. Ighil, F. Prez-Fontn, S. Rougerie, and F. Lacoste, "Mobile and nomadic measurements of the LMS propagation channel at $\mathrm{Ku}$ and Ka bands," in 2015 9th European Conference on Antennas and Propagation (EuCAP), May 2015, pp. 1-4.

[4] S. Scalise, H. Ernst, and G. Harles, "Measurement and Modeling of the Land Mobile Satellite Channel at Ku-Band," IEEE Transactions on Vehicular Technology, vol. 57, no. 2, pp. 693-703, Mar. 2008.

[5] C. Alasseur, S. Scalise, L. Husson, and H. Ernst, "A novel approach to model the land mobile satellite channel through reversible jump markov chain monte carlo technique," IEEE Transactions on Wireless Communications, vol. 7, no. 2, pp. 532-542, Feb. 2008.

[6] S. Scalise, M. A. V. Castro, A. Jahn, and H. Ernst, "A comparison of the statistical properties of the land mobile satellite channel at $\mathrm{Ku}, \mathrm{Ka}$ and EHF bands," in 2005 IEEE 61st Vehicular Technology Conference, vol. 4, May 2005, pp. 2687-2691 Vol. 4.

[7] J. Israel and M. A. Ighil, "Land mobile satellite propagation channel characterization based on rf measurements and fish-eye images," in 2017 IEEE 86th Vehicular Technology Conference (VTC-Fall), Sept 2017, pp. $1-4$. 